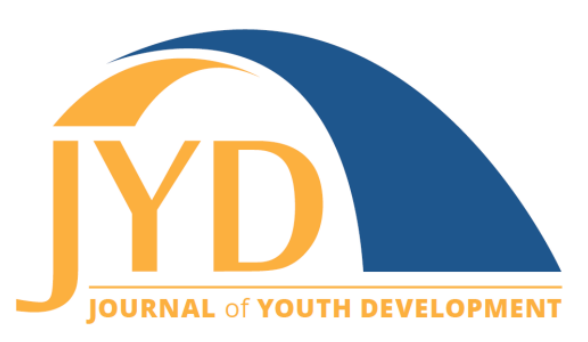

http://jyd. pitt. edu/ | Vol. 14 Issue 4 DOI 10.5195/jyd.2019.771 | ISSN 2325-4017 (online)

\title{
The GIRL Curriculum: Co-Constructing Learning About Body Image Through Empowering After-School Programming
}

\author{
Brianna Meza \\ California State University, Fullerton \\ bricmeza82@csu.fullerton.edu
}

Risto Marttinen

George Mason University

rmarttin@gmu.edu

\begin{abstract}
From a young age, girls experience many influences that may negatively impact how they view their bodies. Many girls are subject to teasing by peers and feel pressure to conform to gender norms. Moreover, the media perpetuates an unattainable and unrealistic image of women, referred to as the ideal female body. Since peers and the media are prominent influences, researchers have implemented curricula as interventions to help girls navigate perceptions of their bodies in a healthy way. Building on prior research, the GIRL curriculum was developed as a semi-structured, co-created curriculum that aimed at engaging girls in critical analysis of media's representation of female bodies in society.

Furthermore, the GIRL curriculum aimed to help girls identify and navigate their possible perceived barriers to physical activity. This curriculum was developed as a response to a lack of resources available for teachers, after-school personnel, and others who work with young girls to engage with the girls about issues of the body in a physically active setting. This program article focuses on the development and implementation of the GIRL curriculum and provides insight, through qualitative analyses, into how a curriculum could help young girls improve their understanding and perception of their bodies and feel empowered. A copy of the co-created curriculum is presented. The researchers urge future practitioners to co-create the curriculum with their participants in order to create opportunities that would allow young girls to view their bodies in a more positive light and feel empowered through a variety of activities.
\end{abstract}

Key words: co-creation, girls, after-school, extra-curricular, leisure, sport

(c) $\mathbf{E Y}$ New articles in this journal are licensed under a Creative Commons Attribution 4.0 License. This journal is published by the University Library System, University of Pittsburgh and is cosponsored by the University of Pittsburgh Press. The Journal of Youth Development is the official peer-reviewed publication of the National Association of Extension 4-H Agents and the National AfterSchool Association. 


\section{Introduction}

Young girls are faced with many influences that greatly affect how they feel and act in regard to their bodies. Many girls view their bodies negatively and begin to desire a thinner body as early as 6 years of age (Dohnt \& Tiggemann, 2006). With these negative views lasting throughout adolescence and into adulthood (Smolak, 2004), researchers have explored the extent to which influences, such as family, friends, peers, and the media, affect girls' views of their bodies (McCabe \& Ricciardelli, 2001, 2003; Smolak, 2012; Wertheim \& Paxton, 2012). While family and friends mostly have a positive impact on girls' lives (Meza, 2019) research has shown that peers (Kostanski \& Gullone, 2007; McLaughlin, Belon, Smith, \& Erikson, 2015) and the media (Bell \& Dittmar, 2011; Tiggemann \& Zaccardo, 2018) can have a detrimental effect on girls' views of their bodies. Girls may experience teasing by peers that negatively influences views of their body (Kostanski \& Gullone, 2007). In addition, young girls have identified teasing by family and peers as a significant influence on girls' body image (McLaughlin et al., 2015). Furthermore, girls worry that they will be viewed negatively and subsequently teased by their peers if they do not conform to gender norms, such as acting feminine (Watson, Eliott, \& Mehta, 2015). Research shows girls' views of their bodies can change on a daily basis depending on the people within their social environment (Davison, 2012).

In addition to peers, the media has been identified as an influence acting on girls' perceptions of their bodies. The media represents women as being pretty, fit, slender, fashionable, and white (Azzarito, 2009), which therefore creates the socially constructed ideal female body (Azzarito, Simon, \& Marttinen, 2016) and contributes to the feminine beauty ideal, which states a female's attractiveness is her most important characteristic (Baker-Sperry \& Grauerholz, 2008). Even though some girls are able to recognize media's portrayal of female bodies as unattainable or unrealistic (Azzarito et al., 2016), girls still identify with the ideal female body and strive to achieve it. This is troublesome, as some girls believe their attractiveness is key to gaining social acceptance (Oliver \& Lalik, 2001). Furthermore, girls who identify with the models portrayed in the media experience a desire to be thin and therefore experience dissatisfaction with their bodies (Bell \& Dittmar, 2011), which then can lead girls to engage in extreme weight loss behaviors that could potentially compromise their health and well-being (Neumark-Sztainer, Paxton, Hannan, Haines, \& Story, 2006). With the potentially harmful effects associated with peer and media influences, researchers have implemented many interventions and practices to help improve girls' perceptions of their bodies, and particularly noteworthy studies (e.g. Azzarito et al., 2016; Oliver, Hamzeh, \& McCaughtry, 2009; Oliver \& Lalik, 2001) have explored the effectiveness of curricula as interventions. These studies are explained below. 


\section{Co-Constructing the GIRL Curriculum}

\section{Curricula Focusing on the Body}

In an attempt to help girls' navigate perceptions of their bodies in a healthy way, researchers have implemented curricula that focus on the body. Many of these curricula have utilized qualitative research methods and have worked with pre-adolescent or adolescent females. Oliver and colleagues (2009) co-created a curriculum with their participants to help girls' identify their perceived barriers to physical activity and, in turn, navigate these barriers. While this study focused more on girls' physical activity barriers, it provided insight into how cocreating a curriculum and actively listening to the participants can engage girls in the curricular activities.

Body-focused curricula have integrated many different strategies to help better understand girls' feelings about their bodies, help them identify their influences, and engage them in critical analysis of those influences. For example, Oliver and Lalik (2001) created and implemented a physical education/language arts curriculum that utilized "storytelling, reflection, and critical analysis" to aid participant's learning processes (p. 307). The girls completed a variety of activities, including a media exploration activity, and used journals as a place to write about how they felt and thought about their bodies. The girls' journals became a space for the girls to have confidential written discussions with the researchers. Similarly, Oliver and Lalik (2004) implemented a curriculum strand into a pre-existing physical education curriculum for adolescent girls. The curriculum also incorporated magazine exploration activities and participant journals. In addition, the curriculum incorporated activities that allowed the girls to choose and analyze an event they thought would be relevant to them and relate to girls' bodies. Lastly, Azzarito and colleagues (2016), who also included magazine exploration activities in their curriculum, focused on engaging participants in critical analysis of media's representation of stereotypical gendered bodies represented in the media. The participants were able to complete their activities from this curriculum in an electronic journal.

These above-mentioned interventions were similar to our research in that they successfully engaged girls in conversations about the body. However, the past curricula differed based on the activities the participants did and the way in which the researchers approached the study. All of these prior studies played a key role in the development of our work. However, Oliver and various colleagues' studies used an approach that aligned with the goals of this study. Therefore, Oliver's research was heavily explored, reviewed, and therefore, influenced the methods behind this study. Prior to commencing the study, the primary researcher 


\section{Co-Constructing the GIRL Curriculum}

communicated with Dr. Oliver via a phone call meeting to discuss her research and get her guidance.

\section{Development of GIRL}

The GIRL (Gaining Insight through Reflective Learning) curriculum was developed because the researchers witnessed first-hand girls' negative talk about the body. During the 2016-2017 school year, the REACH program (see Marttinen, Daum, Banville, \& Fredrick, 2019 for more information) was implemented in an after-school program at a Title I (low-income) school located in southern California. During that time, the volunteer coaches witnessed fifth and sixth grade girls expressing negative remarks about their bodies and avoided certain exercises, such as squats, as they expressed a concern of being watched by their peers. Therefore, in the 2017-2018 school year, the researchers implemented the GIRL curriculum as an extension of the REACH program. The researchers chose to take a similar approach as other researchers who were successful in co-creating a curriculum with their participants (Oliver et al., 2009) and engaging their participants in critical analysis of the ideal female body (Azzarito et al., 2016). The GIRL curriculum was developed as a semi-structured, co-created curriculum, and aimed at engaging girls in critical analysis of media's representation of female bodies in society, and helping girls identify and navigate their possible perceived barriers to physical activity. The main purpose of this program article was to share the GIRL curriculum through a detailed description of the curriculum followed by findings from the implementation. The specific research questions guiding this study were:

1. How do girls in the GIRL program experience its implementation?

2. What challenges arose during implementation and what adaptations were made to the program to address these challenges?

Data are reported elsewhere on students' experiences in GIRL as well as the effect of the program on the participants (Meza, 2019).

\section{Methods}

\section{Procedures}

Permission was obtained from California State University, Fullerton's institutional review board, and the local school district, to conduct the study and implement the GIRL curriculum. The participants in the GIRL sessions submitted parental consent and child assent forms. We approached this study through a qualitative case study approach (Yin, 2017). The researchers 


\section{Co-Constructing the GIRL Curriculum}

collected qualitative data during the implementation of the GIRL curriculum to understand how girls viewed their bodies and how the GIRL curriculum may have improved the girls' perceptions of their bodies. Data were collected through participant interviews with eight Latina girls who participated in the study. Additionally, data consisted of students' weekly journals, participantcreated artifacts, researcher journals, and field notes which were then triangulated to increase trustworthiness and credibility. Two individuals independently coded the data using the constant comparative method (Glaser, 1965). The two independent coders utilized open and axial coding (Marshall \& Rossman, 2013), which led to emerging themes that were then checked by a peer reviewer.

\section{Program Setting}

The GIRL curriculum was implemented during the 2017-2018 school year at a Title I school located in a Southern California school district. Since the GIRL curriculum was an extension of the REACH program, it was implemented at the same school and on the same days as the REACH program. Eleven fifth and sixth grade girls, aged 10 to 11 years, participated in the GIRL curriculum. The girls attended the GIRL sessions for the first 20 to 30 minutes of REACH. Afterward, the participants would join the REACH activities (e.g., soccer, fitness activities, dance, and basketball) for approximately one hour.

All GIRL sessions were completed outside during after-school hours. The GIRL sessions were held at the furthest table from the REACH participants to ensure privacy and security. GIRL sessions were held once a week for the first 9 weeks of implementation. In the $10^{\text {th }}$ week of implementation, the GIRL sessions started being held twice a week, in response to requests by the participants to meet more often. This resulted in 38 structured sessions out of a total of 28 weeks. Each session was designed to have about 30 minutes of activities; however, due to time constraints, some sessions had to be cut short and the activities would be completed during the following session. This article focuses only on the implementation of the GIRL curriculum. To see more information about what the REACH program entailed, see Marttinen \& Fredrick, (2017).

\section{Implementation of the GIRL Curriculum}

Key elements of the curriculum included "check-in" and "choice" activities that allowed the researchers to create or adapt existing activities to appeal to the interest of the participants. Check-in activities were integrated several times throughout the curriculum. During check-in 


\section{Co-Constructing the GIRL Curriculum}

activities the coaches (one of whom was the primary researcher) would ask the girls what they liked, disliked, and suggestions for future sessions. Choice activities were presented in multiple formats. One format of a choice activity would be providing the girls options of how to respond to a series of questions about a specific topic (e.g., writing in journal, drawing, or discussing with researchers). Another format of a choice activity was to the present the girls with multiple topics for a given activity. For example, during a social scenarios activity (described later in this article), the girls would be able to choose one out of several topics surrounding a certain issue. The participants would be encouraged to utilize and refer back to that topic to help them complete the activity. Lastly, the final format in which a choice activity was presented was by allowing the participants to vote on what activity they wanted to complete in the next session.

The GIRL curriculum was divided into four 7-week sections. The first section (weeks 1 through 7) centered on informing the participants about the sessions (e.g., what the sessions would look like, what the participants could expect), and introducing the participants to everyone in the group including the coaches. The activities were designed so that the coaches could learn more about the participants through fun activities (all activities are outlined and briefly described in the Appendix). In addition to introductions, this section's activities sought to develop trust and communication skills among the participants and coaches, which would lay the foundation for the work later in the year.

It was important that during the early stages of the curriculum, the participants felt safe and that they trusted coaches would keep their conversations private. Therefore, the coaches continuously reinforced the idea that whatever was said in the sessions was not to be repeated outside of the sessions and would remain confidential. All of the participants were aware that they had to respect what others in the group had to say and not share the information with anyone else. In addition, the coaches assured the girls that no one other than the coaches would be reading their participant journals, where most of the activities were completed. The coaches informed the girls that they would be reading their journals and would be providing feedback or questions and that the girls would have the option to respond back to them in their journal but only if they wished to. The girls were reminded throughout the entire school year about the privacy and trust policies that were set in place.

The second section (weeks 8 through 14) focused on introducing participants to the foundational GIRL activities. The coaches wanted to introduce the participants to the media exploration activities in order to begin engaging girls in a critical analysis of the ideal female body or feminine beauty ideal. This section also attempted to instill a sense of empowerment by 


\section{Co-Constructing the GIRL Curriculum}

showing videos about girls' physical competence and the importance of trying your hardest to succeed. The coaches used videos from the Always \#LikeAGirl and Dove Self-Esteem project YouTube channels. Always \#Likeagirl embraces the slogan "like a girl" to help girls take pride in being a girl. In addition, Always hopes to help girls build and maintain confidence during puberty and show that girls are physically competent (Our Epic Battle \#LikeAGirl, n.d.). The Dove Self-Esteem project (n.d.) aims to help girls feel confident about their looks. They provide downloadable resources, such as activity packets, for teachers, parents, and youth leaders. Some of these activities were adapted or used as inspiration for a few of the GIRL session activities.

The third section (weeks 15 through 21) focused on giving girls more choice and tried to incorporate activities they said they enjoyed or suggested from the check-in activities, such as having more game-like activities. The first half of the curriculum was fundamental in helping the coaches realize they needed to ensure they were co-creating the curriculum with the girls. Therefore, during this section the coaches actively listened to the participants (Oliver \& Lalik, 2001) to ensure the participants enjoyed the activities. It was important the participants felt a sense of autonomy throughout the entirety of the curriculum implementation. For this specific study, the $15^{\text {th }}$ week was a turning point in the delivery of the curriculum because the coaches realized they needed to offer the participants more choice. Therefore, this section incorporated more question-and-answer discussions and worksheets allowing participants to vote on which activities they did. In addition, participants were also given multiple options for how to complete an activity (e.g. writing in their journal, discussion with coaches, or drawing if applicable).

The fourth and final section (weeks 22 through 28 ) focused on making a final, positive, lasting impact through culminating activities. The coaches attempted to weave in topics of the appearance ideal and the effect it had on girls, reciprocating positivity, and analyzing media's impact on girls' behaviors and thoughts about the body. The activities that were done in this session were activities the girls requested often, and aimed to be more game-like. The final GIRL session consisted of several activities and ended with a final discussion where the girls were able to recall and share valuable things they learned in their sessions, and the coaches made a final statement to the girls. During the final statement both coaches expressed how much they enjoyed their time with the participants throughout the year and explained how they each had learned valuable things while coaching them. The coaches also reiterated the importance of being yourself and loving who you are. 


\section{Co-Constructing the GIRL Curriculum}

Since the GIRL curriculum was co-created with the participants, the curriculum was often adapted prior to each session based on observations the researchers made from the previous session. For example, if participants appeared disengaged, the researchers would implement new ways to get the girls engaged and excited to participate (e.g. making activities more gamelike). In addition, sessions were adapted based on the information received from the participants via the participant journals or activity discussions, which is where most participants would state what they liked or disliked about certain activities. GIRL sessions attempted to engage participants in critical analysis of issues in society, such as how the female body is represented and idealized. The GIRL sessions also attempted to empower the participants. Goals of this curriculum were to (a) impact participants' lives and empower them to practice high levels of confidence and satisfaction with their bodies, and (b) provide a safe space in which girls' could discuss various concerns regarding the body.

We present this curriculum model as a guiding document (see Appendix), as there were none available when we began planning this research. However, it is imperative that girls have autonomy in how they choose to complete activities as well as a voice in co-creating the curriculum at each site. Facilitators should take into consideration the participants' age, maturity level, and demographic background, as well as the culture of the school, community factors, and other such factors in order to tailor the program to the participants' interests. Knowledge of these factors will allow facilitators to build relationships with the participants and adjust the activities to align with the goals of the curriculum. In addition, understanding the participants' background can lead to more successful communication among the participants and more effective co-creation of activities.

\section{Results}

This article will briefly discuss some of the results relevant to how the girls liked or disliked certain aspects of the curriculum and to what extent the GIRL curriculum influenced the girls. The main purpose of this program article is to disseminate and describe the GIRL curriculum as we found there was no evidence-based curriculum available at the time we began this study. The results section is guided by program adaptations and challenges as overarching themes, which are described by how GIRL was a significant influence and a comfortable and safe place. Finally, challenges are presented. For more information on the results surrounding the girls in the program, please see Meza (2019). 


\section{Co-Constructing the GIRL Curriculum}

\section{GIRL - A Significant Influence}

The coaches attempted to positively influence the girls in all of the GIRL sessions. In addition, the coaches tried to instill a sense of empowerment in the girls through multiple activities. For example, on National Girls and Women in Sports Day, the coaches had a conversation with the participants about girls and women who participate in popular sports. This activity was meant to expose the participants to the many triumphs female sport players have had. The treasure box activity, which many girls expressed was one of their favorite activities, allowed the participants to experience positivity by giving and receiving a compliment. Most of the participants indicated they enjoyed these activities and they appreciated having the opportunity to say something nice to someone else in the group.

\section{GIRL - Comfortable \& Safe Environment}

The participants indicated in their interviews that they felt safe and comfortable in the GIRL sessions. In addition, the participants asked the coaches about puberty and transgender, which are typically sensitive topics, and communicated emotions about boys in their journals and discussions. This indicated the girls felt safe and comfortable with the coaches as they discussed topics that appeared to be interesting to them. Moreover, not only did the girls indicate in their interviews that they felt safe asking questions or discussing the various topics in our sessions, but they also told the coaches in their interviews that the that GIRL sessions were the only place to discuss such topics.

The girls' feelings of safety and comfort in the GIRL sessions could be attributed to the relationships the coaches and the girls had. Throughout the entire study the coaches attempted to continue building positive relationships with the participants. These relationships were cultivated through honesty from the coaches, one-on-one talks with the participants, communication via written responses in the girls' journals, and informal discussions before and after the GIRL sessions. The coaches shared several special moments with the participants. On many occasions the girls would be enthusiastic about the GIRL sessions and would run to the tables to begin the activities. In addition, the girls would thank and show appreciation to the coaches for the activities and would be disappointed if one of the coaches had to leave early, even hugging them goodbye on one occasion. The coaches created a special bond with the girls. Although it was documented in the researchers' journal and field notes that the relationship was not always perfect, overall the participants had a positive experience in the GIRL sessions and the relationships with the coaches contributed to that. 
Co-Constructing the GIRL Curriculum

\section{Challenges of the GIRL Curriculum}

Although data point to GIRL acting as a positive influence and able to provide a safe and comfortable environment for the girls, the researchers still faced challenges during the implementation of the curriculum. First, during some sessions the girls were distracted. Since the GIRL sessions shared a space with the REACH program, the girls were sometimes distracted and interested by what the REACH participants were doing. The place where sessions were held posed other issues as well, such as there not being enough table space for the girls. In addition, at times, the girls would have their heads down or appear disengaged and uninterested during the GIRL activities. The girls would often say that they felt tired or unwell whenever they had their head down. The girls had informed the coaches that they liked doing more game-like activities; therefore, the girls could have acted disengaged and uninterested when the activities did not appeal to them.

The coaches adapted activities from past published research (Azzarito et al., 2016; Oliver \& Lalik, 2001; 2004) and the Dove self-esteem project (n.d.). However, at times it was difficult for the coaches to find activities that were suitable and appealing for the participants and also aligned with the goals of GIRL. Therefore, we chose to publish this program article with the curriculum as an open access document, thus providing access to a foundation that educators, coaches, and after-school personnel can use to engage girls and speak to them systematically about issues surrounding the body, media, and growing up as a girl in an age of social media over a prolonged period.

\section{Implications for Practice}

We present the GIRL curriculum over a 28-week period, however, we implore anyone implementing this to modify and adjust the timeline based on student interest and available time. The GIRL curriculum can be taught in a condensed fashion if girls are meeting each day in an after-school program, or it can be extended for more in-depth sessions with a "girls club" or similar on-campus activity. For this particular study, the researchers felt prolonged engagement with the participants was necessary in gaining trust and effective communication skills to contribute to the co-created nature of the study. In doing so, the researchers were able to learn about how the girls viewed their bodies, and therefore attempted to tailor activities in order to target their specific views and perceptions. Some programs may already have a pre-existing relationship with their students, in which case the trust-building activities may be shortened. 
Co-Constructing the GIRL Curriculum

As we previously noted, the GIRL curriculum was semi-structured and co-created. It is recommended that any practitioner using the GIRL curriculum utilize the key elements (check-in and choice activities) to adjust the activities based on their participants' age and interests and myriad other factors. In this type of curriculum it is never a one-size-fits all. Therefore, practitioners should continuously observe and survey their participants to understand what activities would be most suitable and appealing yet convey the importance and message behind a given activity (e.g. being more body positive). In addition, if practitioners feel a particular activity is not applicable or useful for their participants, then they should omit that activity and replace it with something co-constructed. Practitioners should pick and choose the activities, through consultation with participants, to ensure the best fit to the needs and interests of the students.

\section{References}

Azzarito, L. (2009). The panopticon of physical education: Pretty, active and ideally white. Physical Education and Sport Pedagogy, 14(1), 19-39. doi:10.1080/17408980701712106

Azzarito, L., Simon, M., and Marttinen, R. (2016). "Stop Photoshopping!": A visual participatory inquiry into students' responses to a body curriculum. Journal of Teaching in Physical Education, 35, 5469. doi:10.1123/jtpe.2014-0166

Baker-Sperry, L. \& Grauerholz, L. (2003). The pervasiveness and persistence of the feminine beauty ideal in children's fairy tales. Gender \& Society, 15(5), 711-726. doi:10.1177/0891243203255605

Bell, B. T., \& Dittmar, H. (2011). Does media type matter? The role of identification in adolescent girls' media consumption and the impact of different thin-ideal media on body image. Sex Roles, 65, 478-490. doi:10.1007/s11199-011-9964-x

Davison, T. E. (2012). Body image in social contexts. In Encyclopedia of body image and human appearance (pp. 243-249). doi:10.1016/B978-0-12-384925-0.00023-7

Dohnt, H. \& Tiggemann, M. (2006). Body image concerns in young girls: The role of peers and media prior to adolescence. Journal of Youth and Adolescence, 35(2), 141-151. doi:10.1007/s10964005-9020-7

Dove Self-Esteem Project. (n.d.). Retrieved from https://www.dove.com/us/en/dove-self-esteemproject.html

Glaser, B. G. (1965). The constant comparative method of qualitative analysis. Social Problems, 12(4), 436-445. doi:10.2307/798843

Kostanski, M. \& Gullone, E. (2007). The impact of teasing on children's body image. Journal of Child and Family Studies, 16(3), 307-319. doi:10.1007/s10826-006-9087-0 
Journal of Youth Development | http://jyd.pitt.edu/ | Vol. 14 Issue 4 DOI 10.5195/jyd.2019.771

Co-Constructing the GIRL Curriculum

Marshall, C., \& Rossman, G. B. (2013). Designing qualitative research. Thousand Oaks, CA: Sage publications.

Marttinen, R., Daum, D. N., Banville, D., \& Fredrick, R. N. (2019). Pre-service teachers learning through service-learning in a low SES school. Physical Education and Sport Pedagogy, 1-15. doi:10.1080/17408989.2019.1670153

Marttinen, R., \& Fredrick, R. N. (2017). R.E.A.C.H: An After-School Approach to Physical Education. Strategies, 30(1), 8-14. doi:10.1080/08924562.2016.1251862

McCabe, M. \& Ricciardelli, L. (2001). Parent, peer, and media influences on body image and strategies to both increase and decrease body size among adolescent boys and girls. Adolescence, 36(142), 225-240.

McCabe, M. \& Ricciardelli, L. (2003). Sociocultural influences on body image and body changes among adolescent boys and girls. The Journal of Social Psychology, 143(1), 5-26. doi:10.1080/00224540309598428

McLaughlin, E. A., Belon, K. E., Smith, J. E., \& Erickson, S. J. (2015). Mothers' and daughters' beliefs about factors affecting preadolescent girls' body satisfaction. Body Image, 13, 9-17. doi:10.1016/j.bodyim.2014.11.002

Meza, B. (2019). Empowering adolescent girls through an afterschool physical education and character curriculum focusing on the body (Master's thesis). Retrieved from ProQuest.

Neumark-Sztainer, D., Paxton, S. J., Hannan. P. J., Haines, J., \& Story, M. (2006). Does body satisfaction matter? Five-year longitudinal associations between body satisfaction and health behaviors in adolescent females and males. Journal of Adolescent Health, 39(2), 224-251. doi:10.1016/j.jadohealth.2005.12.001

Oliver, K. L., Hamzeh, M., \& McCaughtry, N. (2009). Girly girls can play games / Las niñas pueden jugar tambien: Co-creating a curriculum of possibilities with fifth-grade girls. Journal of Teaching in Physical Education, 28, 90-110.

Oliver, K. L., \& Lalik, R. (2001). The body as curriculum: Learning with adolescent girls. Journal of Curriculum Studies, 33(30), 303-333. doi:10.1080/00220270010006046

Oliver, K. L., \& Lalik, R. (2004). Critical inquiry on the body in girls' physical education classes: A criticalpoststructural perspective. Journal of Teaching in Physical Education, 23, 162-195. doi:10.1123/jtpe.23.2.162

Our Epic Battle \#LikeAGirl. (n.d.). Retrieved from https://always.com/en-us/about-us/our-epic-battle-likea-girl

Smolak, L. (2004). Body image in children and adolescents: Where do we go from here? Body Image, 1 , 15-28. doi:10.1016/S1740-1445(03)00008-1

Smolak, L. (2012). Body image development - girl children. In Encyclopedia of body image and human appearance (pp. 212-218). doi:10.1016/B978-0-12-384925-0.00033-X 
Journal of Youth Development | http://jyd.pitt.edu/ | Vol. 14 Issue 4 DOI 10.5195/jyd.2019.771

Co-Constructing the GIRL Curriculum

Tiggemann, M. \& Zaccardo, M. (2018). 'Strong is the new skinny': A content analysis of \#fitspiration images on Instagram. Journal of Health Psychology, 23(8), 1003-1011. doi:10.1177/1359105316639436

Watson, A., Eliott, J., \& Mehta, K. (2015). Perceived barriers and facilitators to participation in physical activity during the school lunch break for girls ages 12-13 years. European Physical Education Review, 21(2), 257-271. doi:10.1177/1356336X14567545

Wertheim, E. H. \& Paxton, S. J. (2012). Body image development - adolescent girls. Encyclopedia of body image and human appearance (pp. 187-193). doi:10.1016/B978-0-12-384925-0.00029-8

Yin, R. K., (2017) Case study research and applications: Design and methods. Thousand Oaks, CA: Sage Publications. 
Co-Constructing the GIRL Curriculum

\section{Appendix}

\section{GIRL Curriculum Activities and Descriptions}

\begin{tabular}{|l|l|}
\hline \multicolumn{2}{|l|}{ Section 1: Introductions \& Trust Building Activities } \\
\hline Activity & Description \\
\hline $\begin{array}{l}\text { Participant } \\
\text { Introductions }\end{array}$ & $\begin{array}{l}\text { In groups of two, participants will share one exciting thing they did recently. In a } \\
\text { group discussion, participants will share with the group what they shared with their } \\
\text { partners. }\end{array}$ \\
\hline $\begin{array}{l}\text { Participant } \\
\text { Journals }\end{array}$ & $\begin{array}{l}\text { Participants will be introduced to their journals. Participants will get to decorate and } \\
\text { personalize their journals with markers and a variety of stickers. In a group discussion, } \\
\text { participants will go around explaining how they decorated their journals and why they } \\
\text { chose the stickers they did. }\end{array}$ \\
\hline Rose \& Thorn & $\begin{array}{l}\text { Write one "rose," something you are excited or happy about, and one "thorn," } \\
\text { something you are not looking forward to or do not like about the week. }\end{array}$ \\
\hline Passion Tree & $\begin{array}{l}\text { Draw a tree. The trunk of the tree is you, and the branches are anything that makes } \\
\text { you who you are. }\end{array}$ \\
\hline Co-Creating GIRL & $\begin{array}{l}\text { As a group the participants will create a name for the of the GIRL sessions. } \\
\text { Name }\end{array}$ \\
\hline
\end{tabular}

\section{Section 2: Introducing Fundamental Activities}

\begin{tabular}{|l|l|}
\hline Activity & Description \\
\hline Vilways \#Likeagirl & $\begin{array}{l}\text { Girls will be shown a video that shows boys and women portraying girls as physically } \\
\text { incompetent and then showing young girls portraying themselves as physically } \\
\text { competent and able to be athletic. The girls will then be engaged in a discussion about } \\
\text { the video made them feel. }\end{array}$ \\
\hline Always \#Likeagirl & $\begin{array}{l}\text { Girls will be shown a video that shows girls may fail but that they can always come } \\
\text { back from failure to try again. The girls will be asked to respond to questions about } \\
\text { the video and how it relates to the \#Likeagirl video. }\end{array}$ \\
\hline Magazine & $\begin{array}{l}\text { The girls will go through magazines and tag photos or quotes that they like. The girls } \\
\text { will be given a magazine packet that has photocopies of each of the photos they } \\
\text { tagged or liked and will be asked to categorize the photos and quotes in their journals. } \\
\text { Then, the girls will be asked to record in their journals why and how they categorized } \\
\text { the pictures and quotes. The girls will also be asked to write about what pictures or } \\
\text { quotes they think send messages about girls' bodies. The coaches will have a } \\
\text { discussion about the common and different themes they saw within each girls' }\end{array}$ \\
\hline
\end{tabular}


Co-Constructing the GIRL Curriculum

\begin{tabular}{|l|l|}
\hline Check-In Activity & $\begin{array}{l}\text { magazine packets and her responses to the activities. } \\
\text { far and ask for suggestions for future activities. }\end{array}$ \\
\hline $\begin{array}{l}\text { Rose \& Thorn } \\
\text { Activity }\end{array}$ & $\begin{array}{l}\text { Participants will write one rose, something they liked about their week and one thorn, } \\
\text { what they disliked about their week or wished was different. }\end{array}$ \\
\hline Social Scenarios & $\begin{array}{l}\text { The participants will be given a scenario that presents an issue. In groups, the girls } \\
\text { will need to come up with a solution to the scenario, assign roles, and act out the } \\
\text { scenario in front of the coaches and other group members. }\end{array}$ \\
\hline
\end{tabular}

\section{Section 3: Giving more choice}

\begin{tabular}{|c|c|}
\hline Activity & Description \\
\hline Paper Game & $\begin{array}{l}\text { There will be } 11 \text { pieces of paper, each with a different word (Beauty, Girl, } \\
\text { Inspirational, Strong, Boy, Positive, Negative, Healthy, Body, Athlete, Model). Through } \\
\text { different games the girls will get a piece of paper and be asked to write about } 3 \text { things } \\
\text { related to the word on the paper. }\end{array}$ \\
\hline Social Scenarios & $\begin{array}{l}\text { The participants will be given a scenario that presents an issue. In groups, the girls } \\
\text { will need to come up with a solution to the scenario, assign roles, and act out the } \\
\text { scenario in front of the coaches and other group members. }\end{array}$ \\
\hline $\begin{array}{l}\text { National Girls \& } \\
\text { Women in Sports } \\
\text { Day }\end{array}$ & $\begin{array}{l}\text { The coaches will talk about different female athletes' accomplishments and discuss the } \\
\text { history and background of Title IX. }\end{array}$ \\
\hline About You & The girls will be asked to draw themselves and write an "about me parag \\
\hline $\begin{array}{l}\text { The Perfect } 5^{\text {th }} \& \\
6^{\text {th }} \text { Grade Girl: } \\
\text { Choice Activity }\end{array}$ & $\begin{array}{l}\text { The girls will have the option to draw, write, or engage in a discussion with the } \\
\text { coaches. All topics will revolve around who the girls think is the perfect } 5^{\text {th }} \& 6^{\text {th }} \text { grade } \\
\text { girl is (e.g. what does she look like, what characteristics does she have?) }\end{array}$ \\
\hline $\begin{array}{l}\text { Check-In Activity } \\
\text { Start, Keep, } \\
\text { Improve }\end{array}$ & $\begin{array}{l}\text { The girls will be asked to write down what they think the coaches can start doing in } \\
\text { the sessions, what they should keep doing, and what they can improve on. }\end{array}$ \\
\hline Voting Ballot & $\begin{array}{l}\text { The girls will be given descriptions of } 4 \text { activities. The girls will vote on which activity } \\
\text { they want to do next. }\end{array}$ \\
\hline $\begin{array}{l}\text { Beauty from } \\
\text { Around the World }\end{array}$ & $\begin{array}{l}\text { The girls will be given different facts about beauty traditions from various cultures } \\
\text { around the world. The girls will run to true or false signs posted on a wall to show } \\
\text { whether they think the statement is true or false. }\end{array}$ \\
\hline $\begin{array}{l}\text { International } \\
\text { Women's Day }\end{array}$ & $\begin{array}{l}\text { Today's topic will be about International Women's Day. The girls will have a discussion } \\
\text { about what it's like to be a female and how it feels to have a holiday dedicated to }\end{array}$ \\
\hline
\end{tabular}


Co-Constructing the GIRL Curriculum

\begin{tabular}{|c|c|}
\hline & women. \\
\hline $\begin{array}{l}\text { Spot the Difference } \\
\text { (Adapted from the } \\
\text { Dove self-esteem } \\
\text { project) }\end{array}$ & $\begin{array}{l}\text { With their partners, the girls will have to identify the differences between two before } \\
\& \text { after photoshop photos. Coaches will engage girls in discussion about photoshop } \\
\text { and retouching. }\end{array}$ \\
\hline $\begin{array}{l}\text { Treasure Boxes } \\
\text { Part } 1\end{array}$ & $\begin{array}{l}\text { The girls will decorate boxes with stickers and markers to personalize. They will give } \\
\text { and receive a compliment in their box to and from other girls in the group based on } \\
\text { different topics. }\end{array}$ \\
\hline \multicolumn{2}{|c|}{ Section 4: Culminating Activities } \\
\hline Activity & Description \\
\hline $\begin{array}{l}\text { Treasure Boxes } \\
\text { Part } 2\end{array}$ & $\begin{array}{l}\text { The girls will give and receive a compliment in their box to and from other girls in the } \\
\text { group based on different topics. }\end{array}$ \\
\hline $\begin{array}{l}\text { Appearance Ideal } \\
\text { Magazine } \\
\text { Exploration }\end{array}$ & $\begin{array}{l}\text { The girls will go through their magazine packets and choose two people who they } \\
\text { think is the prettiest or best looking. The girls will be asked to analyze, compare, and } \\
\text { contrast those persons physical characteristics. }\end{array}$ \\
\hline True \& False & $\begin{array}{l}\text { The girls will be read various facts about women's random accomplishments or about } \\
\text { females and their troubles with their jobs. The girls will run to true or false signs. The } \\
\text { coaches will engage the participants in a discussion about the issues some women } \\
\text { face and the accomplishments they have had. }\end{array}$ \\
\hline Social Scenarios & $\begin{array}{l}\text { The participants will be given a scenario that presents an issue. In groups, the girls } \\
\text { will need to come up with a solution to the scenario, assign roles, and act out the } \\
\text { scenario in front of the coaches and other group members. }\end{array}$ \\
\hline School Maps & $\begin{array}{l}\text { The girls will draw their schools and will mark areas they feel happy, safe, and } \\
\text { comfortable, areas where they feel unsafe or uncomfortable, areas where they have } \\
\text { positive influences, and areas they wish they had more influences. }\end{array}$ \\
\hline $\begin{array}{l}\text { Preparing for last } \\
\text { GIRL session }\end{array}$ & The girls will be asked what activities they want to do for the last session. \\
\hline Final GIRL session & $\begin{array}{l}\text { The girls will do the group-chosen activities: compliment tag, scavenger hunt, and } \\
\text { final discussion about GIRL. }\end{array}$ \\
\hline
\end{tabular}

Note. Some activities were completed more than once with a different topic or subject. Lessons are in order based on what section they were completed in. 